\title{
L'identité française entre repli sur soi et ouverture à l'autre Alain Finkielkraut vs François Durpaire
}

\section{L'identité française entre repli sur soi et ouverture à l'autre Alain Finkielkraut vs François Durpaire Laila Yousri Mohamed Abd El Ghany French department, Faculty of Arts, Alexandria University.}

\section{laila.yosry@alexu.edu.eg}

\begin{abstract}
Cette étude porte sur deux visions différentes de l'identité française dans une tentative de voir si les descendants des immigrés postcoloniaux sont considérés comme pleinement Français. Dans la première partie, nous abordons L'Identité malheureuse d'Alain Finkielkraut où il rejette le multiculturalisme et défend le droit des Français de protéger leur propre culture contre toutes les pratiques étrangères qui la mettent en péril. La violence des jeunes issus de l'immigration, le port du voile, l'inégalité hommes-femmes sont incompatibles avec la culture française et cela suffit pour rejeter les musulmans de France hors la nation tout en les jugeant inassimilables. Dans la deuxième partie, nous abordons Nous sommes tous la France! de François Durpaire qui a une vision plus ouverte de l'identité française. Ces jeunes sont reconnus par la loi comme Français et il n'est plus question de mettre en doute leur amour et leur loyauté pour la France. La volonté de vivre en commun et l'attachement aux valeurs républicaines doivent être le fondement de la nation, indépendamment de l'origine ethnoculturelle. Défendant le droit à la différence, Durpaire trace les grandes lignes d'une politique d'intégration et de lutte contre les discriminations dans l'espoir de voir les Français unis dans la diversité.
\end{abstract}

Keywords: identité; multiculturalisme; intégration; immigration; vivre-ensemble

En mai 2007, le président français, Nicolas Sarkozy, a créé un ministère de l'Immigration, de l'Intégration, de l'Identité nationale et du Développement solidaire. Parmi ses compétences, on compte : les naturalisations et la délivrance des certificats de nationalité française, la collecte des données sur l'immigration et l'adoption de politiques visant à la contrôler, la détermination des conditions d'entrée et de séjour des ressortissants étrangers ainsi que leur intégration et la promotion des valeurs républicaines auprès d'eux. 


\section{L'identité française entre repli sur soi et ouverture à l'autre Alain Finkielkraut vs François Durpaire}

La création de ce ministère, dont le nom associe l'immigration et l'identité nationale, a laissé supposer que les étrangers constituent un problème pour le pays. Ce constat a été confirmé par le débat lancé en 2009 sur l'identité française et sur son rapport à la diversité culturelle, couramment appelée "multiculturalisme », terme qui désigne la coexistence de plusieurs cultures dans un même pays. Bien que ce ministère ait été supprimé en novembre 2010, le débat sur l'identité nationale continue de faire polémique en France.

Dans cette recherche, nous étudierons deux visions différentes de l'identité française en s'appuyant sur L'Identité malheureuse du philosophe Alain Finkielkraut et Nous sommes tous la France! de l'historien François Durpaire.

À travers cette étude, nous abordons une question qui peut paraitre choquante à certains: les descendants des immigrés postcoloniaux sont-ils considérés comme pleinement Français? Autrement dit, sont-ils une partie intégrante de la nation française ? C'est en répondant à cette question qu'on pourrait comprendre la crise identitaire qui traverse la France en ce début du XXI ${ }^{\mathrm{e}}$ siècle.

\section{Finkielkraut et sa vision exclusive de l'identité nationale}

\section{Le déclin de l'identité française sous l'effet de l'immigration}

Dans L'Identité malheureuse, Finkielkraut représente l'immigration comme une menace pour l'identité française. La société française, auparavant homogène, est devenue cosmopolite avec l'augmentation de l'immigration de peuplement. Ce changement s'est opéré à partir de 1976 lorsque le gouvernement Chirac a autorisé le «regroupement familial », donnant ainsi le droit aux travailleurs étrangers, et surtout non européens, de faire venir en France leurs familles proches (conjoint et enfants) qui peuvent plus tard acquérir la nationalité française. Loin de voir dans l'immigration de peuplement un avantage pour la France et une chance de compenser le vieillissement de la population et la baisse de la natalité, Finkielkraut trouve qu'elle menace l'homogénéité de la société française et conduit au changement des mœurs :

Avec le passage d'une immigration de travail à une immigration familiale, les autochtones ont perdu le statut de référent culturel qui était le leur dans les périodes précédentes de l'immigration. Ils ne sont plus prescripteurs. 


\section{L'identité française entre repli sur soi et ouverture à l'autre Alain Finkielkraut vs François Durpaire}

Quand le cybercafé s'appelle "Bled.com" et que la boucherie ou le fastfood ou les deux sont halal, ces sédentaires font l'expérience déroutante de l'exil. [...] Ils n'ont pas bougé, mais tout a changé autour d'eux. [...] Ils se sentent devenir étrangers sur leur propre sol. (Finkielkraut, 2013, pp. 118119)

Les termes «autochtones » et « sédentaires » employés par Finkielkraut pour désigner les vrais Français ne relèvent-ils pas d'une vision ethnique du peuple français uni par le sang et la culture ? Finkielkraut distingue, en fait, les Français de souche, auxquels il associe les Français d'origine européenne qui ont réussi leur assimilation à la communauté nationale ${ }^{1}$, et les Français issus de l'immigration postcoloniale qui, au lieu de se fondre dans la nation et d'assimiler la culture du pays qui les accueille, qui est la seule culture légitime aux yeux de Finkielkraut, veulent conserver leur culture d'origine et vivre en France comme ils vivent chez eux.

Face à cette situation, les Français appartenant aux couches populaires ont tendance à déserter les banlieues des grandes villes qui sont majoritairement peuplées d'immigrés car ceux-ci constituent une main-d'œuvre moins chère. Ils vont s'installer dans ce que Christophe Guilluy appelle la « France périphérique ${ }^{2}$ » (Algalarrondo, 2014) où ils s'opposent à la construction de logements sociaux qui pourraient abriter des immigrés et qui les mettraient de nouveau en contact avec eux. Les Français de souche se replient donc sur eux-mêmes et refusent de vivre avec les Français issus de l'immigration qui, ayant un mode de vie différent, vivent en communautés selon leurs traditions religieuses ou culturelles. Il en résulte qu'il y a des territoires entiers où vivent des gens qui n'ont rien de français et où règnent des mœurs étrangères. D'où ce constat de Finkielkraut : «Plus l'immigration augmente et plus le territoire se fragmente. » (Finkielkraut, 2013, p. 119)

Cette volonté de vivre à l'écart des étrangers témoigne du refus du peuple de la société cosmopolite mais elle est jugée raciste par ceux qui la défendent. Cela pousse Finkielkraut à dénoncer le discours moralisateur des élites qui, au lieu

\footnotetext{
1. Finkielkraut en est un exemple : il est fils d'immigrés juifs polonais et a été élu à l'Académie française en avril 2014.

2. La France périphérique comprend des zones urbaines, comme les petites et moyennes villes, des zones périurbaines (ce sont les villages qui ont été intégrés dans l'enceinte d'une ville proche) et des zones rurales (la campagne). La périphérie est loin de tous les pouvoirs qui se concentrent dans les métropoles et subit plus les effets de la mondialisation.
} 


\section{L'identité française entre repli sur soi et ouverture à l'autre Alain Finkielkraut vs François Durpaire}

de comprendre l'inquiétude des Français de ne plus se sentir chez eux, «prônent le multiculturalisme et la tolérance pour la diversité » (Todorov, 2012, p. 231). Ils ne se rendent pas compte que l'immigration de peuplement constitue un danger pour la France puisqu'elle risque de mener à l'islamisation de la société française. Finkielkraut accuse d'ailleurs ceux qui plaident pour l'ouverture à l'autre de dénier la réalité puisque dans la vie quotidienne, ils ne font que pratiquer le séparatisme qu'ils reprochent au peuple : ils n'habitent pas en banlieue, n'utilisent pas les transports en commun et leurs enfants ne fréquentent pas les écoles des quartiers populaires. (Ligne droite, 2018) Bref, « ils prônent l'abolition des frontières tout en érigeant soigneusement les leurs. Ils célèbrent la mixité et ils fuient la promiscuité. » (Finkielkraut, 2013, p. 122) Ce décalage entre ce qu'on dit et ce qu'on fait conduit Finkielkraut à dénoncer la bien-pensance des élites et son corollaire le politiquement correct.

\section{La mise en cause de l'antiracisme contemporain}

Finkielkraut rejette le discours antiraciste politiquement correct qui vise à contrôler le langage en stigmatisant les propos racistes et à dicter la manière dont il faut se comporter à l'égard des minorités. Il exige que la pensée de chacun soit conforme à l'idéologie dominante et celui qui ose penser différemment est rigoureusement critiqué. C'est ce que Finkielkraut appelle, d'une manière péjorative, la bien-pensance ou la bonne pensée par opposition à la pensée mauvaise des racistes et des xénophobes.

Hantés par les crimes du passé (l'extermination des Juifs et la colonisation), les adeptes du discours antiraciste prônent une culture de la repentance et de l'excuse et dénoncent, au nom des droits de l'homme, toute sorte de discrimination qui risque de menacer la paix sociale et de nuire à la cohésion de la société. Loin de voir les effets nocifs de l'immigration, ils la considèrent comme une chance pour la France de réparer les torts du passé :

La France, l'Europe, 1'Occident ont beaucoup péché en voulant mettre

l'Autre à la raison : l'occasion leur est maintenant offerte d'être purifiés par

l'Autre d'eux-mêmes et de leur passé coupable. (Finkielkraut, 2013,p. 101)

Selon la logique de la repentance, il faut ouvrir les portes à l'immigration de peuplement et non l'arrêter. Selon la même logique, il ne faut pas non plus parler d'appartenance, il faut proscrire l'expression « Français de souche » parce qu'elle 


\section{L'identité française entre repli sur soi et ouverture à l'autre Alain Finkielkraut vs François Durpaire}

est discriminatoire : elle distingue le « nous » du « eux » et conduit à l'exclusion de l'autre.

Les tenants du politiquement correct tendent à sacrifier l'héritage culturel français à des valeurs universelles qui dépassent tous les particularismes qui divisent la société et ouvrent la voie à la stigmatisation d'une partie de la population. Ils rejettent ainsi la prédominance de la culture française au nom de la reconnaissance de la diversité culturelle. Ayant honte du passé colonial de la France, ils font « du mépris de soi un signe de tolérance et d'ouverture au monde » (Castillo, 2014, p. 55). Ils pratiquent «l'oikophobie», terme emprunté au philosophe anglais Roger Scruton pour désigner « la haine de la maison natale, et la volonté de se défaire de tout le mobilier qu'elle a accumulé au cours des siècles »(Finkielkraut, 2013, p. 101). Finkielkraut regrette ainsi la renonciation du gouvernement au projet de créer une Maison de 1'Histoire de France en 2011 et, avant elle, l'abandon du débat sur l'identité nationale à la suite de l'opposition de certains intellectuels à sa continuation. Au lieu de chercher à protéger le patrimoine français, on contribue par ce genre de décision à sa dissolution et à l'effacement de tout ce qui constitue la civilisation française.

Neutraliser l'identité domestique [...] au profit des identités diasporiques et minoritaires ; faire la place, en désinfatuant la nation d'elle-même, à toutes les appartenances et à toutes les orientations (religieuses, ethniques, régionales, sexuelles) marquées du sceau de la différence : telle est la voie qui s'impose si l'on veut promouvoir la diversité. (Finkielkraut, 2013, p. 104)

Pour Finkielkraut, les adeptes du multiculturalisme sont non seulement oikophobes mais aussi xénophiles : ils ont de la sympathie à l'égard des étrangers et invitent les Français à s'ouvrir à eux même, à les accueillir sans pourtant chercher à les assimiler ou à les convertir à la culture française. Selon eux, il faut plutôt respecter les différences culturelles et leur permettre d'exprimer leur particularité et leur singularité. C'est ainsi que la France pourrait expier les fautes qu'elle a commises à l'égard des anciens colonisés. À la dérive xénophobe, les antiracistes opposent ce que Finkielkraut appelle «le romantisme pour autrui ${ }^{1}$ »

\footnotetext{
1. Il convient de rappeler que le romantisme allemand était une réponse à l'universalisme abstrait des Lumières. Ambitieux de faire table rase d'une société fondée sur la hiérarchie, les philosophes des Lumières soutenaient que tous les hommes, de par leur nature humaine, sont égaux et ont, par conséquent, les mêmes droits indépendamment
} 


\section{L'identité française entre repli sur soi et ouverture à l'autre Alain Finkielkraut $v s$ François Durpaire}

(Finkielkraut, 2013, p. 100) : ils accordent aux immigrés le droit d'être fiers de leurs origines mais, paradoxalement, ils privent les Français du même droit sous peine d'être traités de racistes.

La repentance $[\ldots]$ a mis le concept de Français de souche au pilori et la "fierté de venir de..." au pinacle. L'enracinement des uns est tenu pour suspect et leur orgueil généalogique pour "nauséabond", tandis que les autres sont invités à célébrer leur provenance et à cultiver leur altérité. Ici on dénonce tout à la fois un privilège exorbitant et un fantasme mortifère ; là on encourage ardemment le sens de la continuité et de la fidélité à ses racines. (Finkielkraut, 2013, p. 109)

Pour prévenir la montée du nationalisme qui vante l'enracinement, les antiracistes mettent en valeur le métissage de la population française. Ils affirment que la France a toujours été une terre d'immigration, que les Français sont des sangs-mêlés et que le changement démographique n'est pas un phénomène récent. Loin d'y voir le signe du « grand remplacement ${ }^{1}$ » décrit par Renaud Camus, ils insistent sur le fait que la France s'est constituée d'un brassage continu de populations de différentes origines et de cultures diverses. Bref, tout ce qui distingue le même de l'autre est méprisé ou condamné au profit de la célébration de l'altérité des autres. Les Français sont invités à s'ouvrir aux identités étrangères au lieu de se replier sur leur héritage et de le revendiquer orgueilleusement. Mais Finkielkraut refuse que cette ouverture se fasse aux dépens de la haine de soi.

Les antiracistes sont soucieux de dénoncer « la haine de l'Autre » mais ils passent sous silence le racisme anti-blanc et ferment les yeux sur «l'Autre haineux» (Finkielkraut, 2013, p. 181) qui déteste la France et sa culture. Cette haine de la France est liée, selon Finkielkraut, à la haine des juifs et elle est le fait d'une minorité musulmane qui veut imposer ses lois (la charia) et son mode de vie en France. D'après Finkielkraut, la haine de la France et l'antisémitisme qui l'accompagne se traduisent par la violence qui sévit en banlieue et qui ne peut être

\footnotetext{
de leur appartenance sociale. Les romantiques allemands ont rejeté cette vision abstraite de l'homme et ont soutenu que tout homme est situé : il «naît dans une société déjà donnée » (Finkielkraut, 1987, p. 25) dont il hérite la culture. À la suite des romantiques, les nationalistes français ont affirmé que l'individu n'existe plus en tant que tel mais il fait partie d'une nation. Bref, il est enraciné dans l'espace et dans le temps : il appartient à une terre et possède des ancêtres qui lui transmettent leur manière de vivre et de penser.

1. Selon Renaud Camus, les immigrés ont plus d'enfants que les Français ce qui fait qu'au bout d'une ou deux générations, leur nombre dépasserait celui des Français de souche qui seraient une minorité sur leur propre sol, amenant leur disparition.
} 


\section{L'identité française entre repli sur soi et ouverture à l'autre Alain Finkielkraut $v s$ François Durpaire}

justifiable par la brutalité policière ou par des conditions sociales telles que le chômage, la misère et l'exclusion subie. En pointant du doigt les causes sociales de la violence, on présente les coupables comme des victimes en révolte contre les inégalités dont ils souffrent. On ne fait ainsi qu'excuser la violence et nier la part de responsabilité individuelle des personnes qui se comportent avec violence. En procédant de la sorte, les antiracistes censurent la réalité et s'abstiennent d'expliquer cette violence par l'origine de ceux qui la commettent ${ }^{1}$. Ils se contentent de faire la morale aux Français qui rejettent l'autre violent, au lieu de condamner sa violence et y voir un danger qui menace la tranquillité de la société française.

La violence que Finkielkraut associe de manière exclusive aux jeunes musulmans de France n'est, selon lui, qu'une manière de se venger du manque de reconnaissance de la société à leur égard. Finkielkraut ne nie pas que la reconnaissance joue un rôle fondamental dans le développement de la personne et dans la constitution de l'identité collective. Tout être humain a besoin d'être aimé et respecté par ceux qui l'entourent, « de se sentir faire partie d'un groupe reconnaissable » (Todorov, 2012, p. 233), ce qui lui donne une image positive de lui-même et l'aide à avoir une bonne estime de soi. Mais les immigrés postcoloniaux sont perçus comme différents par leur apparence, leur langue et leurs coutumes et sont, par conséquent, dépréciés parce qu'ils ne maîtrisent pas bien la langue française, ne connaissent pas les codes culturels français et « réussissent moins bien que les autres » (Todorov, 2008, p. 106). Cette situation défavorable a un impact négatif sur leur respect de soi. Alors ils intériorisent cette « image dépréciative d'eux-mêmes » et «prolongent par l'autodénigrement le mépris dont ils sont l'objet» (Finkielkraut, 2013, p. 200). Poussés par la seule exigence d'être respectés et acceptés tels qu'ils sont, les jeunes en colère recourent à la violence dans une tentative de réhabiliter un sentiment de dignité bafoué par l'exclusion sociale. Dans ce contexte, tout mot mal placé ou regard de travers sont considérés comme un manque de respect qui justifie le recours à la violence.

Partant de là, Finkielkraut reconnaît la nécessité de donner aux jeunes issus de l'immigration la reconnaissance à laquelle ils aspirent mais en même temps, et d'une manière paradoxale, il condamne leur soif de reconnaissance et l'absence

\footnotetext{
1. Frédéric Debomy souligne cette contradiction dans la pensée de Finkielkraut qui, d'une part, rejette les «déterminismes sociaux » et considère les jeunes des banlieues «comme des sujets pleinement autonomes » (Debomy, 2017, p. 60), mais, d'autre part, suppose que leurs comportements sont déterminés par leur origine.
} 


\section{L'identité française entre repli sur soi et ouverture à l'autre Alain Finkielkraut vs François Durpaire}

d'humilité chez eux. Leurs comportements violents qu'on nomme « incivilités » les distinguent des Français pour qui le respect d'autrui est une valeur importante parce qu'il est le fondement de la vie en société. C'est lui qui nous « fait donner la préséance à l'autre - "Je vous en prie", "Après vous" " - et nous empêche de lui porter atteinte ou de lui faire du mal. « Le respect d'autrui impose [ainsi] une limite à l'expansion du moi, discipline ses pulsions, corrige son narcissisme. » (Lévy, 2011)

Face à la montée de la violence et des incivilités, à l'abandon des bonnes manières et au non-respect des règles de vie en communauté, Finkielkraut appuie la décision du ministère de l'Éducation nationale, en 2013, de retourner à l'enseignement de la morale laïque à l'école primaire et au second degré pour former les élèves au respect de l'autre et leur rappeler qu'ils ont non seulement des droits mais aussi des devoirs à l'égard de leurs concitoyens. Les contraintes de la civilité nous obligent à retenir notre violence ce qui rend la vie en société supportable.

Au lieu de culpabiliser le système qui n'arrache pas l'injustice sociale dont ces fils d'immigrés sont victimes, Finkielkraut dénonce leur grossièreté, contribuant ainsi à perpétuer un préjugé, assez répandu dans la société française, qui stigmatise les jeunes des banlieues. D'ailleurs, en attribuant la violence aux seuls musulmans, il tombe dans les travers de l'essentialisation ${ }^{1}$ comme si tous les musulmans avaient les mêmes caractères et agissaient de la même manière. Le fait de généraliser et d'établir une relation de cause à effet entre l'identité d'origine de ces jeunes et la violence que certains d'entre eux peuvent manifester permet à Finkielkraut de passer sous silence les facteurs sociaux qui ont conduit à ce phénomène. En tant que responsables de leurs actes, il les appelle à renoncer à leur «nocence originelle », c'est-à-dire à leur volonté de nuire aux autres, car la non-violence, ou l'« in-nocence » (Finkielkraut, 2013, p. 165) comme l'appelle Renaud Camus, est ce qui permet de renforcer le lien social et le sentiment d'appartenance à la communauté. Pour l'instant, le souci d'autrui ne doit pas empêcher les élites de voir l'autre tel qu'il est : un ennemi qui hait la France et qui

1. C'est un procédé qui «consiste précisément à définir globalement une population par une ou quelques caractéristiques de nature biologique, culturelle, ou religieuse. Dès lors, les membres de » cette population ne sont plus considérés comme des individus distincts mais plutôt comme des « "exemplaires" d'un même "type" » (Jamin, 2015, p. 37). En d'autres termes, "l'individu est réduit [...] à un échantillon de son groupe d'appartenance » (Debomy, 2017, p. 58). 


\section{L'identité française entre repli sur soi et ouverture à l'autre Alain Finkielkraut vs François Durpaire}

a en outre des mœurs brutales qui sont incompatibles avec les mœurs adoucies des Français.

\section{Finkielkraut : fervent défenseur de l’identité française}

Bien qu'il mette l'accent sur l'autre différent de soi et le perçoive comme un danger, Finkielkraut s'abstient de se qualifier de raciste ou de populiste ${ }^{1}$. En fait, il rejette l'alternative entre le politiquement correct et le politiquement abject. Face à l'incapacité de la France, et de l'Europe en général, de faire face à la crise économique et aux flux migratoires, les populistes désignent l'immigré comme le bouc émissaire de tous les maux qui rongent la société française et font des musulmans l'objet de toutes les stigmatisations. L'immigré musulman est perçu comme un envahisseur qui ne respecte pas les valeurs de la République et qui cherche à imposer sa religion aux autres ou à islamiser la France. Il est, de ce fait, un facteur de désintégration de la société. Pour empêcher que la peur de l'étranger ou la haine des musulmans, d'ailleurs assimilés à des intégristes en puissance, ne se transforment en violence à leur égard ${ }^{2}$, les adeptes du politiquement correct affirment que la société doit être inclusive et que la cohésion nationale ne doit pas se faire sur le dos du bouc émissaire, c'est-à-dire sur le rejet d'une catégorie de la population française.

Refusant l'un et l'autre, Finkielkraut prétend défendre une position intermédiaire inspirée de la pensée de Lévis-Strauss :

Nous devons [...] tirer les leçons du $\mathrm{XX}^{\mathrm{e}}$ siècle en faisant la place à l'altérité. Mais ne sommes-nous pas nous-mêmes l'autre de l'Autre ? Et cet autre n'a-t-il pas le droit lui aussi d'être et de persévérer dans son être ? (Finkielkraut, 2013, p. 128)

En outre, il signale ultérieurement :

1. Le terme «populisme » désigne des mouvements politiques qui, s'opposant aux élites au pouvoir, prennent le
parti du peuple et jouent sur ses craintes pour renverser le système et ses représentants. Ils se distinguent par « leur
nationalisme affiché, un nationalisme se présentant comme un combat identitaire et souverainiste, [...] supposant
les nations menacées par la mondialisation et les multiples processus qu'elle implique » (Taguieff, 2015, p. 43).
2. Comme ce qui s'est passé en Norvège le 22 juillet 2011 lorsque l'extrémiste de droite, Anders Breivik, a fait
exploser une bombe près du siège du gouvernement à Oslo, tuant 8 personnes, puis a tiré sur les participants à un
camp d'été des Jeunes Travaillistes norvégiens, causant la mort de 69 adolescents. Ce double attentat ne vise pas
directement les musulmans mais plutôt les dirigeants politiques qui encouragent l'occupation du pays par les
immigrés musulmans. Une autre attaque à l'encontre des musulmans a eu lieu au Canada le 29 janvier $2017:$ un
étudiant de 27 ans a tiré sur les fidèles qui priaient dans la grande mosquée de Québec, faisant 6 morts et 19 blessés. 


\section{L'identité française entre repli sur soi et ouverture à l'autre Alain Finkielkraut vs François Durpaire}

Il nous faut combattre la tentation ethnocentrique de persécuter les différences et de nous ériger en modèle idéal sans pour autant succomber à la tentation pénitentielle de nous déprendre de nous-mêmes pour expier nos fautes. [...] Notre héritage qui ne fait certes pas de nous des êtres supérieurs mérite d'être préservé et entretenu. (Finkielkraut, 2013, p. 129)

S'appuyant sur Race et culture, conférence donnée par Lévi-Strauss à l'Unesco en 1971, Finkielkraut soutient que défendre son identité et sa culture n'est pas un crime et qu'il faut distinguer le racisme de la xénophobie. Celle-ci désigne la haine ou le rejet de l'étranger, c'est-à-dire de celui qui est différent au niveau de l'apparence, de la culture ou du mode de vie. Le xénophobe n'a aucune tendance à penser la différence en termes de hiérarchie (supériorité ou infériorité). Il a tout simplement peur de l'étranger qui menace son identité culturelle. Quant au racisme, il consiste à diviser l'humanité en plusieurs races dont chacune possède un patrimoine génétique (des caractères physiques héréditaires) qui détermine les capacités intellectuelles et les inclinations morales de ses membres. Le racisme désigne donc une tendance à classifier les hommes en fonction de la couleur de la peau, de la culture ou de la religion, tout en considérant certains groupes humains comme inférieurs aux autres, justifiant ainsi leur domination par les groupes supérieurs.

Si le racisme est une passion criminelle qu'il faut combattre, la xénophobie, au contraire, est une attitude normale parce que l'attachement des individus ou des groupes «à certaines valeurs [les] rend partiellement ou totalement » (LéviStrauss, 1983, p. 15) imperméables aux valeurs et aux normes d'une autre culture. Cette fermeture est même nécessaire, selon Lévi-Strauss, pour préserver la diversité des cultures qui, en entrant en contact, tendent à s'homogénéiser. La xénophobie n'est, selon lui, condamnée que si elle est accompagnée de la répression des valeurs culturelles qu'on rejette ou de leurs représentants.

Partant de là, Finkielkraut admet qu'à l'étranger, le sentiment d'étrangeté est normal puisqu'on n'est pas effectivement chez soi et on doit, par conséquent, respecter les identités étrangères et se débarrasser des préjugés ethnocentriques. Mais à l'intérieur, il n'est pas normal de se sentir étranger chez soi et on doit absolument faire respecter la culture française et ses valeurs. Il ne faut pas ainsi culpabiliser les Français de souche qui se retirent dans la périphérie pour fuir la mixité avec les étrangers et être entre soi. Leur attitude n'a rien à voir avec le 


\section{L'identité française entre repli sur soi et ouverture à l'autre Alain Finkielkraut vs François Durpaire}

racisme. Il s'agit plutôt d'une sorte de crispation sur leur identité et d'un mécanisme d'autodéfense. Les Français au même titre que les autres ont le droit de conserver leur culture et de la transmettre à leurs descendants. Mais n'y a-t-il pas là une certaine contradiction ? Finkielkraut reconnaît le droit des Français de souche de préserver leur particularisme tout en niant ce droit aux jeunes issus de l'immigration qui doivent absolument s'intégrer pour être considérés comme pleinement Français. Cette contradiction découle du fait que Finkielkraut présuppose que «la reconnaissance de l'altérité exige le sacrifice de sa propre identité ». Ce qui n'est pas vrai puisque, comme le souligne Michel Terestchenko, $l^{\prime}$ '« un des principes de base de la conception interculturaliste est [...] que l'accueil et le respect des minorités ethniques et religieuses par la culture hôte doit se faire dans la préservation de son héritage, de ses valeurs fondatrices et de son identité » (Terestchenko, 2013). D’une part, les membres de ces minorités doivent apprendre la langue française et respecter les lois de la République. D'autre part, ils ont le droit, selon le principe d'égalité, « de vivre conformément à » leurs «traditions culturelles» (Choquet, 2015, p. 416) ou religieuses sans être stigmatisés ou discriminés.

Finkielkraut se réclame de Lévi-Strauss mais sa position ne contredit-elle pas la pensée du fameux anthropologue ? Celui-ci reconnait, en effet, le droit de chacun de défendre sa propre culture. Mais ne trouve-t-on pas dans le principe de « relativisme culturel » préconisé par Lévi-Strauss une incitation à élaborer un modèle de gestion de la diversité culturelle qui s'éloigne de l'assimilation ? En admettant que toutes les cultures sont égales et qu'aucune d'elle n'a le droit d'imposer son système de valeurs aux autres, Lévi-Strauss défend le droit de chacun de résister à l'uniformisation. S'il affirme, dans un premier temps, que les cultures doivent se maintenir à distance les unes des autres pour échapper à l'uniformisation, il soutient, dans un second temps, que «cette incommunicabilité » entre les cultures est « relative » (Lévi-Strauss, 1983, p. 15). Nous vivons dorénavant dans un monde presque sans frontières où les cultures sont condamnées à entrer en contact les unes avec les autres. Cela revient à dire que les rencontres entre les cultures ne doivent pas dépasser certaines limites ce qui permettrait à chacune d'elle de sauvegarder son particularisme. La coexistence pacifique des cultures ou le simple contact entre elles n'entraînent donc pas nécessairement leur dégénérescence. C'est plutôt l'excès de communication qui entraîne l'homogénéisation culturelle. 


\section{L'identité française entre repli sur soi et ouverture à l'autre Alain Finkielkraut $v s$ François Durpaire}

Dans son souci de protéger à tout prix l'identité française menacée par le contact avec l'autre, Finkielkraut conçoit Race et culture comme une invitation à la guerre puisque des cultures foncièrement différentes et cherchant à se défendre les unes des autres ne peuvent que s'entrechoquer. Il fait aussi preuve d'un « racisme différentialiste » (Taguieff, 1985) en postulant que les différences entre les cultures sont irréductibles. Des valeurs comme la laïcité ou l'égalité hommefemme sont, pour lui, des valeurs françaises que les immigrés arabo-musulmans sont incapables de comprendre. De même, des gestes comme le port du voile, l'obstination à manger halal ${ }^{1}$ ou le refus de la mixité entre hommes et femmes sont considérés comme une sorte de résistance à ces valeurs.

\section{Le voile et la laïcité française}

Par crise d'intégration, Finkielkraut désigne en premier lieu le refus des immigrés d'assimiler la culture française. Loin de vanter l'enracinement, Finkielkraut affirme qu'on peut s'attacher à la France par le cœur tout comme par l'hérédité. La France n'est pas une nation organique à laquelle on appartient par le sang. Un individu d'origine étrangère peut devenir Français s'il fait preuve de son amour de la France en assimilant le mode de vie français. Or, ce n'est pas le cas des jeunes issus de l'immigration postcoloniale. Preuve en est le débat sur la question du voile.

La crise a commencé le 18 septembre 1989 lorsque le principal d'un collège de Creil, dans l'Oise (banlieue parisienne), a décidé d'exclure trois élèves à la suite de leur refus d'enlever le voile en classe. Le 6 octobre, la décision est mise en vigueur et les jeunes filles sont interdites d'accès au collège. Des voix se sont élevées pour défendre le libre exercice du culte : il ne faut pas interdire l'entrée à l'école à certaines élèves en raison de leurs convictions religieuses. Lionel Jospin, alors ministre de l'Éducation nationale, a plaidé pour le dialogue avec les familles tout en rappelant que « l'école française est faite pour éduquer, pour intégrer, pas pour rejeter »(Finkielkraut, 2013, p. 26). Pour le gouvernement français de l'époque, la laïcité de l'école se limite à la neutralité de l'enseignement fourni (les

\footnotetext{
1. Conformément à la pensée de Lévi-Strauss, le fait de porter le voile ou de manger halal peut être vu comme la manifestation de la volonté des musulmans de France de préserver leur culture. Cette volonté est légitime tant qu'on n'empêche pas les autres de s'habiller ou de manger comme ils le veulent. Finkielkraut trouve, au contraire, dans la pensée de Lévi-Strauss un prétexte pour justifier son rejet de pratiques sociales et religieuses étrangères à la société française en insinuant que si l'autre ne veut plus renoncer à sa culture, il fera « mieux de la cultiver chez lui » (Stoczkowski, 2007, p. 23).
} 


\section{L'identité française entre repli sur soi et ouverture à l'autre Alain Finkielkraut vs François Durpaire}

programmes scolaires ne doivent « véhiculer aucune idéologie qui puisse heurter la conscience des élèves ») (Finkielkraut, 2013, p. 28), à la neutralité des enseignants (ils ne doivent porter aucun signe religieux ni afficher leurs convictions personnelles) et à la neutralité des bâtiments (aucun signe religieux ne doit être accroché aux murs). L'élève, quant à lui, n'est pas un agent de l'État et en tant que bénéficiaire du service public, il a le droit de "manifester sa croyance » (Finkielkraut, 2013, p. 29). C'est ce qu'exprime l'avis du Conseil d'État du 27 novembre 1989 qui voit que le port des signes religieux à l'école n'est pas incompatible avec le principe de la laïcité qui implique la liberté de pratiquer son culte dans l'espace public et le respect des différentes croyances. Toutefois, l'avis interdit « les signes ostentatoires, qui constituent en eux-mêmes des éléments de prosélytisme ou de discrimination » (Finkielkraut, 2013, p. 30) ce qui risque d'entraver le bon déroulement de l'enseignement. Le gouvernement adopte donc une position libérale sur la question du voile : la religion relève de la sphère privée et l'État n'a pas le droit de promulguer une loi qui interdirait le port $\mathrm{du}$ voile dans les écoles publiques mais c'est aux chefs d'établissement d'examiner chaque cas à part. Comme il n'y avait pas de critère qui permet de distinguer les signes discrets des signes ostensibles, les exclusions des élèves voilées se sont multipliées, étant donné que certains chefs d'établissement considéraient «que le port du voile est en soi un élément de prosélytisme » (Finkielkraut, 2013, p. 30).

En 2003, le président de la République, Jacques Chirac, a mis en place une commission, présidée par Bernard Stasi, un homme politique de grande considération, et chargée de réfléchir sur l'application du principe de la laïcité dans la République. Le rapport de la commission Stasi recommande l'interdiction des signes religieux dans les écoles publiques pour que ces dernières restent un lieu d'émancipation et de liberté. Le 15 mars 2004, une loi est promulguée dans ce sens et, tenant à effacer toute référence à la religion dans la sphère publique, elle était étendue aux mères voilées accompagnant leurs enfants lors des sorties scolaires. Il est nécessaire de souligner que la loi de 2004 sur le voile s'oppose à l'esprit de la loi de 1905 qui est un gage de liberté. Ladite loi n'interdit la manifestation des convictions religieuses dans l'espace public que si elle trouble l'ordre public ou nuit à la liberté des autres car si la religion est une affaire privée, cela ne signifie pas qu'elle doit être invisible dans l'espace public. Le 12 octobre 2010, une autre loi est promulguée, interdisant cette fois-ci le voile intégral (la 


\section{L'identité française entre repli sur soi et ouverture à l'autre Alain Finkielkraut $v s$ François Durpaire}

burqa) qui dissimule le visage dans l'espace public. Finkielkraut souligne que la burqa n'est pas interdite en tant que signe religieux mais parce qu'elle contredit les principes de fraternité et de civilité : la femme qui arbore le voile intégral se donne le droit de voir autrui tout en l'empêchant de la voir ; elle refuse ainsi d'établir une relation réciproque avec les autres et d'entrer en contact avec eux.

Le rapport Stasi a marqué un changement dans la conception de la laïcité en France. La neutralité de l'État vis-à-vis des religions ne signifie plus désormais la passivité du premier mais plutôt son engagement « en faveur de l'autonomie de jugement des citoyens et de leur émancipation à l'égard de traditions religieuses imposées » (Choquet, 2015, p. 324). Finkielkraut souligne ainsi que «tolérer le foulard islamique, ce n'est pas accueillir un être libre (en l'occurrence une jeune fille), c'est ouvrir la porte à ceux qui ont décidé de lui faire plier l'échine » (Finkielkraut, 2013, p. 36). Finkielkraut attire l'attention sur le fait qu'on a affaire à des individus mineurs qui ne sont pas totalement libres en raison de leur jeune âge et qui doivent obéir à leurs familles et se soumettre aux usages de leurs communautés. Autoriser le port du voile à l'école contribue donc à renforcer le pouvoir de la communauté sur ses membres tandis qu'en l'interdisant, on donne aux jeunes filles l'occasion de se libérer des contraintes imposées par leur groupe d'appartenance.

Finkielkraut défend ici la conception républicaine de la liberté qui rejette toute forme de domination de l'individu et qui voit que le rôle de la République est de garantir l'autonomie des citoyens. Partant de là, la loi de 2004 n'est ni une sorte de discrimination envers la communauté musulmane ni une forme d'oppression des individus par l'État. Par le biais de cette loi, l'État cherche à réduire les pressions exercées par les communautés sur leurs membres en vue de conserver leurs traditions respectives. Il vise aussi à protéger la liberté individuelle en préservant les jeunes de toute influence religieuse afin de les rendre capables de décider par eux-mêmes sans subir aucune pression ${ }^{1}$. À l'école, les élèves doivent mettre de côté leurs croyances religieuses pour qu'ils puissent les juger avec une certaine autonomie quand ils retournent à la sphère privée. C'est ce que Finkielkraut a déjà exprimé dans un manifeste qu'il a co-signé avec d'autres

1. Critiquant cette loi, Todorov se demande avec un peu d'ironie : «Ne devrait-on pas interdire le port de signes religieux à la maison aussi, pour empêcher que les enfants connaissent les choix religieux de leurs parents et qu'ils soient ainsi influencés dans leurs futures décisions ? Pense-t-on sérieusement que voir une femme porter le foulard suffit pour que l'élève ne sache plus accéder aux "valeurs républicaines" ? (Todorov, 2012, p. 228) 


\section{L'identité française entre repli sur soi et ouverture à l'autre Alain Finkielkraut vs François Durpaire}

intellectuels en 1989 et où il critique la flexibilité du gouvernement lors de l'affaire des « foulards de Creil » :

Il faut que les élèves aient le loisir d'oublier leur communauté d'origine et de penser à autre chose qu'à ce qu'ils sont pour pouvoir penser par euxmêmes. [...] Le droit à la différence qui vous est si cher n'est une liberté que s'il est assorti du droit d'être différent de sa différence. Dans le cas contraire, c'est un piège, voire un esclavage. (Finkielkraut, 2013, p. 27)

Pour Finkielkraut, les filles voilées sont en quelque sorte des femmes aliénées soumises à l'autorité de leurs parents ou de leurs communautés. Mais n'y a-t-il pas des filles qui ont volontairement choisi de porter le voile ? En les obligeant à l'enlever pour pouvoir entrer à l'école, ne porte-t-on pas atteinte à la liberté de conscience ? La liberté de pratiquer la religion de son choix comprend celle de manifester sa religion, donc la possibilité de porter des signes ou des habits qui manifestent son appartenance religieuse. Pour Finkielkraut, le libre choix de porter le voile est peu important et ne change rien à la réalité : elles ont choisi d'être soumises et « le fait de valider sa propre diabolisation ne rend pas celle-ci plus acceptable » (Finkielkraut, 2013, p. 54). Il faut les libérer malgré elles en les obligeant à enlever le voile. Mais est-ce qu'elles seraient ainsi vraiment libérées ? On les pousse, au contraire, à se replier sur elles-mêmes, à « rester cloîtrées chez elles » et à ne pas «participer à la vie publique » (Todorov, 2012, p. 226), donc à ne pas s'intégrer à la nation. D'ailleurs, en les contraignant à se dévoiler, on limite leur liberté d'action au lieu de la renforcer puisqu'on juge qu'elles sont incapables « de gérer elles-mêmes leur vie » et que, par conséquent, «elles doivent se soumettre aux décisions des autres » (Todorov, 2012, p. 226) qui lui dictent comment s'habiller.

Plaidant en faveur de la prohibition du voile à l'école, Finkielkraut trouve un autre argument pour justifier la loi de 2004 : ces jeunes filles qui portent le voile ne le font pas uniquement par obligation religieuse mais aussi pour s'affirmer et afficher leur identité culturelle : «Avec ce petit tract d'étoffe, elles manifestent leur être, elles veulent qu'on les perçoive pour ce qu'elles sont. » (Finkielkraut, 2013, p. 52) Permettre le port du voile, c'est donc accorder un droit ou un privilège à un groupe culturel quelconque qui lui permet de maintenir sa particularité et qui l'exempte de se plier aux règles générales. Or, tous les citoyens sont égaux devant la loi et cette égalité suppose que la loi s'applique 


\section{L'identité française entre repli sur soi et ouverture à l'autre Alain Finkielkraut vs François Durpaire}

indifféremment à tous les citoyens sans distinction d'origine ou de religion. Octroyer un droit à une partie de la population, en l'occurrence le port du voile pour les musulmans, est une sorte de discrimination qui va à l'encontre de l'idéal républicain d'égalité. L'État est censé être aveugle aux différences, la neutralité de l'État étant la seule garantie d'égalité.

Mais nous avons vu qu'avec la loi de 2004, la neutralité s'étend aux individus dans l'espace public dans le but de sauver l'unité nationale. L'école étant le «creuset où se fabrique le vivre-ensemble » (Finkielkraut, 2013, p. 20), elle ne doit pas reproduire les clivages ethnoculturels qui divisent la société. Elle doit, par contre, arracher les élèves à leur particularisme pour les libérer de toute tutelle extérieure et les rendre capables de choisir librement. Elle doit aussi développer leur esprit critique et les former à la citoyenneté. C'est à l'école que les élèves apprennent à vivre ensemble en nourrissant chez eux le sentiment d'appartenance à la nation et le respect des valeurs républicaines qui doivent l'emporter sur leur appartenance à telle ou telle communauté. C'est ainsi qu'on peut mettre fin au communautarisme qui est, selon Finkielkraut, l'équivalent d'« un vivre à distance » (Finkielkraut, 2013, p. 39). Pour lui, le vivre-ensemble consiste à se conformer à la règle générale et à respecter les lois de la République même si elles contredisent les convictions religieuses ou les pratiques culturelles propres à chaque communauté. Il dénonce ainsi l'existence de certaines pratiques communautaires à l'école qui sont loin de renforcer la cohésion sociale comme : le refus de la mixité et la présentation de certificats médicaux de complaisance qui permettent aux jeunes filles musulmanes de se faire dispenser des cours de gymnastique et de piscine; la faible fréquentation des cantines scolaires bien qu'elles proposent des plats de substitution sans porc ; la contestation de certains contenus d'enseignement pour des raisons religieuses ${ }^{1}$. Finkielkraut souhaite que l'État puisse mettre fin à ces pratiques qui nuisent au vivre-ensemble comme il l'a fait pour le voile à l'école.

\footnotetext{
1. Des écrivains comme Rousseau ou des œuvres comme Tartuffe de Molière et Madame Bovary de Flaubert sont rejetés parce qu'ils sont jugés haram (interdits). Même l'enseignement de l'histoire n'échappe pas à la catégorisation religieuse : on se méfie d'une histoire nationale accusée d'être fondée sur le mensonge. Ainsi, des sujets comme l'extermination des Juifs d'Europe ou le conflit israélo-palestinien provoquent-ils des divisions au sein des classes dans les quartiers sensibles et mettent en relief le « refus de partager une histoire commune » (Finkielkraut, 2013, p. 115).
} 


\section{L'identité française entre repli sur soi et ouverture à l'autre Alain Finkielkraut vs François Durpaire}

\section{Le voile et le statut de la femme en France}

En interdisant le port du voile ou de la burqa, la France défend non seulement les principes de laïcité et d'égalité mais aussi « la relation spécifique qu'elle a instaurée entre les hommes et les femmes » (Finkielkraut, 2013, p. 159). Pour l'opinion française, le voile pose le problème du vivre-ensemble entre les deux sexes : il «coupe, une fois pour toutes, le monde en deux et règle la coexistence des sexes sur le principe d'une stricte séparation» (Finkielkraut, 2013, p. 54). Le voile ne sert pas uniquement à marquer l'appartenance religieuse mais il a aussi pour fonction de réduire la visibilité de la femme, de cacher la beauté féminine pour ne pas attirer le regard des hommes. Pour Finkielkraut, le voile est le symbole de la claustration des femmes ${ }^{1}$ qui, étant à la fois désirables et désirantes, doivent être soustraites aux regards des hommes pour éviter le déshonneur. Le voile vise à la fois à refroidir les hommes et à les mettre à l'abri de toute tentation sexuelle ainsi qu'à protéger les femmes de la concupiscence des hommes qui pourraient perdre tout contrôle en voyant une femme séduisante. En bref, souligne Finkielkraut,

Le voile [...] réduit pornographiquement les relations entre les sexes au désir, et le désir lui-même à une pulsion bête et violente. [...] Ce bout de tissu signifie aux femmes que leur présence est obscène, que tout en elles et sur elles renvoie à leur anatomie et qu'elles constituent, de ce fait, un trouble potentiel à l'ordre public. (Finkielkraut, 2013, pp. 77-78)

Ainsi, dans certains quartiers de France, les femmes non voilées doiventelles adopter le style masculin sinon elles seront victimes de harcèlement. Elles sont obligées de porter le pantalon, et plus précisément le pantalon de jogging, ou un survêtement qui dissimule leur féminité et les met à l'abri des insultes. En revanche, celles qui osent porter une jupe ou s'habiller comme une femme sont traitées de putes et exposées au mépris de leur entourage. Cela mène Finkielkraut à constater que, dans ces quartiers, il y a une analogie implicite entre le pantalon, vêtement masculin par excellence, et «symbole de la modernité, et le voile, symbole de la tradition et réservé aux femmes » (Finkielkraut, 2013, p. 73). Ce qui rapproche ces deux vêtements apparemment différents c'est qu'ils cachent la

1. En considérant le voile, d'une manière générale, comme le symbole de l'oppression des femmes, Finkielkraut ne tient pas compte de toute la réalité. Le voile n'est une oppression que s'il est imposé par la force. Beaucoup de femmes choisissent librement de le porter et elles ne doivent pas être stigmatisées parce qu'elles ont le droit de disposer de leurs corps. 


\section{L'identité française entre repli sur soi et ouverture à l'autre Alain Finkielkraut vs François Durpaire}

féminité de la femme. Les femmes françaises, dans leur combat pour l'égalité, ont milité pour avoir le droit à porter le pantalon : les vêtements féminins empêchaient les femmes d'exercer certains métiers uniquement réservés aux hommes et c'est en portant le pantalon qu'elles se libèrent de leur condition subalterne. Les femmes issues de l'immigration, quant à elles, réclament « le droit à la féminité » (Finkielkraut, 2013, p. 76). Finkielkraut résume ainsi les objectifs de l'association Ni putes ni soumises (NPNS), fondée en 2003 pour combattre toutes les formes de violence contre les femmes, si bien qu'on a l'impression que le voile constitue un obstacle à l'émancipation féminine :

Elles [les femmes des "quartiers"] veulent pouvoir, par leur vêtement, par leur maquillage, par leur coquetterie, collaborer à la beauté du monde, sans être aussitôt accusées de tenter le diable, par les gardiens de la vertu, et de collaborer à leur domination, par les tenants de la théorie du genre. (Finkielkraut, 2013, p. 76)

Derrière le voile se trouve une conception dégradante de la femme : elle est objet de désir et doit par conséquent se voiler. Celle qui refuse de porter le voile est vue comme une femme dépravée et celle qui cède au désir est d'autant plus maltraitée car, dans ce contexte, toute relation hors mariage est perçue comme un danger pour l'intégrité masculine. Le mépris de la femme et la rudesse à son égard sont, selon Finkielkraut, l'une des raisons de la violence qui règne dans les quartiers dits sensibles :

Ce qui rend dur et brutal, c'est la mauvaise réputation de la douceur, c'est une définition de la virilité qui implique le dédain et même le dégoût de celles qui "veulent bien", c'est, pour tout dire, la vigilance sans faille que la misogynie collective exerce sur le comportement de chaque individu. (Finkielkraut, 2013, p. 74)

Le voile, en tant que symbole de l'exclusion sociale des femmes, s'oppose à la galanterie qui, tout en reconnaissant le pouvoir de séduction du corps féminin, suppose que le désir masculin peut être civilisé et que l'homme peut maîtriser ses pulsions. Cette tradition est une spécificité de la culture française qui, par son rejet de la violence à l'égard des femmes, met en lumière la différence entre les vrais Français qui respectent la femme et les Français issus de l'immigration qui l'oppriment. La galanterie est un savoir-vivre et un signe de raffinement social. Elle est née avec l'essor des salons littéraires au XVII ${ }^{\mathrm{e}}$ siècle. Ces salons étaient 


\section{L'identité française entre repli sur soi et ouverture à l'autre Alain Finkielkraut vs François Durpaire}

tenus par les femmes aristocratiques qui recevaient régulièrement chez elles de grandes personnalités (hommes ou femmes) pour faire la conversation et apprendre les bonnes manières. La nature ayant donné à l'homme la force physique, il doit compenser ce privilège par «la délicatesse du comportement » (Finkielkraut, 2013, p. 58) : il doit ainsi traiter les femmes avec beaucoup d'égards et de considération. Le galant homme s'abstient de recourir à la violence ou à l'intimidation dans sa relation avec l'autre sexe. Il «ne se jette pas sur les femmes » (Finkielkraut, 2013, p. 59) et doit chercher à les séduire en leur faisant la cour. La galanterie est en ce sens un moyen de rendre hommage aux femmes en exaltant leur beauté. Elle est avant tout un « jeu érotique ouvert» (Finkielkraut, 2013, p. 65) qui permet de régler les rapports entre les deux sexes sans qu'il y ait dépravation comme le fait remarquer Claude Habib :

Approcher des femmes touchait jusqu'ici à la profanation. La galanterie permettait au contraire d'approcher les femmes les plus belles, de leur parler d'amour toute la journée sans que cela soit un déshonneur pour personne. Elle laissait penser que l'on pouvait séjourner dans cette bulle de l'amour explicite et exprimé sans que cela n'ait de suite. (Habib, 2018)

La galanterie «présuppose une visibilité du féminin, [...] une joie d'être visible » (Finkielkraut, 2013, p. 53). C'est en ce sens qu'elle s'oppose au voile qui est lié à d'autres pratiques répressives qui relèguent les femmes au second plan et qui les cloîtrent dans la sphère privée. Néanmoins, la galanterie à la française (dont certains rituels subsistent encore) est, de nos jours, fortement critiquée par les féministes parce qu'elle consacre la domination masculine et rend la femme dépendante de l'homme dans les menus gestes. Ce que les Français considèrent comme un art de la séduction est vu ailleurs comme une indignité et une humiliation de la femme. Par «son badinage et ses compliments » (Finkielkraut, 2013, p. 67), le galant homme avilit la femme et la rabaisse au rang d'objet. Les femmes françaises sont ainsi accusées d'encourager «l'inconduite des hommes par leur complaisance » (Finkielkraut, 2013, p. 66) puisqu'elles prennent pour un compliment ce qui est perçu comme harcèlement sexuel par d'autres.

En faisant de la galanterie un trait caractéristique des Français tout en mettant en avant ses bienfaits, Finkielkraut l'utilise comme un instrument qui lui permet d'exclure les Français issus de l'immigration de la nation, justement parce qu'ils manquent de courtoisie. Pour Finkielkraut, la violence contre les femmes 


\section{L'identité française entre repli sur soi et ouverture à l'autre Alain Finkielkraut vs François Durpaire}

est le propre des jeunes musulmans de France, comme si les Français de souche étaient incapables de violence et comme si les femmes n'étaient maltraitées et soumises que dans la culture musulmane. Finkielkraut a certes le droit de critiquer certaines pratiques qui lui semblent incompatibles avec les valeurs de la République mais il a tort de généraliser dans le but d'accentuer les différences culturelles entre les communautés.

\section{François Durpaire : porteur d'une vision inclusive de l'identité française}

Refusant ces interprétations identitaires qui divisent davantage la société, Durpaire voit qu'il faut plutôt chercher ce qui distingue les Français des autres nationalités, c'est-à-dire ce qui unit l'ensemble des citoyens au-delà des différences qui les séparent.

\section{La remise en cause de l'intégration à la française}

Si pour Finkielkraut, la crise identitaire dont souffre la France s'explique par le fait que les Français se sentent étrangers dans leur propre pays, Durpaire trouve, au contraire, qu'elle est due à l'incapacité des enfants d'immigrés postcoloniaux de se sentir Français. Ayant officiellement la nationalité française, ils se disent d'origine étrangère, s'identifient à la nationalité de leurs parents et ne se sentent pas chez eux en France puisque les gens ne les reconnaissent pas comme Français et leur demandent sans cesse d'où ils viennent. En réalité, ils ne sont pas d'origine étrangère comme leurs parents qui sont, eux, nés à l'étranger et ont acquis par la suite la nationalité française. Si on refuse de les considérer comme Français et si on les traite toujours d'immigrés, c'est parce qu'ils ont une apparence différente de celle de la majorité des Français, qu'il s'agisse de la couleur de la peau ou des vêtements portés. C'est pourquoi on utilise le terme «minorités visibles » pour distinguer les immigrés provenant des anciennes colonies françaises des immigrés européens arrivés en France dans les années trente. Les premiers sont en effet considérés comme moins français que les seconds qui passent souvent inaperçus. D'où cette conclusion de Durpaire :

Ce qui compte n'est pas l'identité, mais la visibilité de l'identité, qui détermine la légitimité de l'appartenance à notre communauté. [...] La question de l'identité - celui avec qui je me reconnais comme identique se double de la question de la visibilité. Je reconnais comme identique - et 


\section{L'identité française entre repli sur soi et ouverture à l'autre Alain Finkielkraut vs François Durpaire}

"français" - celui qui me ressemble, et comme différent - donc "étranger"

- celui qui ne me ressemble pas... (Durpaire, 2012, p. 22)

Ce critère utilisé pour déterminer qui appartient à la nation ne reconnaît comme Français que ceux qui parviennent à s'assimiler à la majorité. Mais s'il est possible d'effacer toute appartenance communautaire ou religieuse dans la sphère publique, il est presque difficile de changer la couleur de la peau. Si l'on continue de retenir comme critère d'être Français l'apparence physique, il y aura toujours des personnes qui trouvent des difficultés à s'intégrer à la communauté nationale. D'où cette constatation : «Être Français, ça ne se voit pas. » (Durpaire, 2012, p. 37) Au lieu de jeter la faute sur les jeunes issus de l'immigration et de les accuser d'être responsables de l'échec de leur intégration comme le fait Finkielkraut, Durpaire dénonce le modèle d'intégration français qui ne parvient pas à leur transmettre la fierté d'être Français :

C'est en effet la communauté d'accueil qui détient la clef de l'assimilation. Je ne peux pas me sentir membre d'une communauté qui ne m'accepte pas. Si la France, comme une grande famille, ne me fait pas une place, je me replie naturellement vers la seule que je connaisse, celle de mes parents et de leur pays d'origine. Il n'y a pas défaut d'intégration, mais défaut d'acceptation. (Durpaire, 2012, p. 35)

L'intégration est « un processus réciproque » (Choquet, 2015, p. 422) ou à double sens qui implique à la fois que les immigrés s'adaptent à la langue et à la culture françaises mais également que la société d'accueil soit ouverte à la diversité. Or, on a des jeunes qui sont nés en France, y ont suivi leur scolarité, parlent la langue française et ont même parfois de grands-parents de nationalité française. Pourtant, ils ne sont pas considérés comme des Français à part entière. On leur demande fréquemment leurs origines, on les ramène toujours à leurs racines pour dire qu'ils sont étrangers, on leur demande sans cesse des preuves d'intégration et ils sont soumis plus que les autres aux contrôles d'identité en raison de leur différence visible. Pourquoi ce traitement différencié ? Ne sont-ils pas des Français comme les autres?

\section{La nationalité française : fondement de la citoyenneté}

Pour Durpaire, « Être Français, c’est avoir des papiers français » (Durpaire, 2012, p. 57), c'est-à-dire être reconnu par la loi comme citoyen français. L'identité 


\section{L'identité française entre repli sur soi et ouverture à l'autre Alain Finkielkraut vs François Durpaire}

nationale n'a donc rien à voir avec la communauté d'origine ni le partage d'un mode de vie ou de traits culturels communs. Durpaire rappelle que sous l'Ancien Régime, la nationalité était octroyée en vertu du droit du sol : les enfants nés de parents étrangers dans le royaume de France étaient considérés comme Français alors que ceux nés de parents français hors du royaume ne l'étaient pas. D'ailleurs, le roi accordait des lettres de naturalité aux étrangers vivant sur les territoires du royaume mais, en même temps, toute personne qui décidait de quitter le royaume sans retour perdait sa nationalité. (Weil, 2003, p. 323) Bref, être Français, c'était lié à la présence sur le sol français qui était, à son tour, le synonyme d'être sujet d'un même souverain. (Choquet, 2015, pp. 281-282) Avec le Code civil de 1804, la primauté a été donnée au droit du sang et la nationalité était transmise par la filiation paternelle: un enfant né d'un père français était automatiquement Français. En 1889, une loi a été promulguée, reconnaissant que la nationalité est également acquise par le fait de naître sur le territoire français. On retourne donc au droit du sol pour deux raisons : d'une part, parce qu'à partir de 1851, la France est devenue un pays d'immigration et l'institution du droit du sol était un moyen pour faciliter l'intégration des descendants des immigrés. (Weil, 2003, p. 321) D'autre part, parce qu'après la défaite de 1871 et la perte de l'Alsace-Lorraine, la France avait besoin de soldats et c'est en reconnaissant officiellement comme Français les étrangers nés sur son territoire qu'elle pourrait les contraindre au service militaire. (Perrault, 2013) Depuis ce temps, le droit du sol est reconnu en France au même titre que le droit du sang et Durpaire s'oppose à ceux qui veulent l'abolir ou qui réduisent l'importance de la carte d'identité en tant que symbole de l'appartenance à la nation. Ce document administratif officiel « définit des Français, tout court » (Durpaire, 2012, p. 63) : il ne distingue pas entre ce qu'on appelle les Français de souche et les Français d'origine étrangère, déniant ainsi l'idée qu'il y a des Français plus légitimes que d'autres, une légitimation illusoire fondée sur l'apparence et qui ouvre la voie à la discrimination d'une partie de la population. Sans ce document, souligne Durpaire, «notre accent, notre ancienneté sur le territoire, notre couleur de peau, notre religion seraient autant de critères de distinction : aucun Français ne serait plus l'égal d'aucun autre » (Durpaire, 2012, p. 64).

Si la possession d'une carte d'identité ne suffit pas, pour certains, pour prouver que ces jeunes issus de l'immigration sont bien Français, cela met en cause la légitimité de leur présence en France et discrédite l'État de droit. Si on 


\section{L'identité française entre repli sur soi et ouverture à l'autre Alain Finkielkraut vs François Durpaire}

leur dénie la qualité des Français parce qu'ils n'ont pas de racines françaises, ne portent pas un nom français ou ne mangent pas de porc, cela revient à dire que ces critères socioculturels sont plus pertinents que la carte d'identité pour définir ce qu'est être Français. Or, la nationalité est un lien purement juridique qui attache une personne à un pays déterminé selon les règles fixées par l'État. La France se définit comme un État-nation ce qui veut dire que la nation est une entité politique qui désigne l'ensemble des citoyens de l'État ${ }^{1}$. Elle est donc perçue comme une communauté de citoyens, fondée sur des valeurs universelles, plutôt qu'une communauté d'origine, de langue ou de culture. Ceux qui veulent supprimer le droit du sol mettent en avant une nation ethnique basée sur la filiation. Ils prônent le repli sur soi et le rejet de l'autre (celui qui n'est pas Français d'origine mais l'est devenu par naturalisation ou du fait de sa naissance en France). La conception civique de la nation suppose, par contre, une société ouverte, capable d'intégrer de nouveaux citoyens, quelles que soient leurs origines. Le concept de citoyen permet de transcender les différences ethnoculturelles entre les individus et associe l'identité française au fait d'appartenir à une même communauté politique.

Si l'on retourne à la carte d'identité comme preuve de la nationalité française, Durpaire met l'accent sur le fait qu'elle n'exige pas de déclarer son amour pour la France. La citoyenneté française est liée à l'acquisition de la nationalité ; c'est un statut juridique où les sentiments ne comptent pas. Voilà pourquoi, Durpaire rejette le slogan «La France, aimez-la ou quittez-la! » qui a été adopté par le Front national dans les années 1980 puis repris par Nicolas Sarkozy, lui-même fils d'immigrés, dans un discours prononcé en avril 2006 et où il a dit : "S'il y en a que ça gêne d'être en France, je le dis avec le sourire mais avec fermeté, qu'ils ne se gênent pas pour quitter un pays qu'ils n'aiment pas ${ }^{2}$. » En doutant de l'amour des Français issus de l'immigration pour la France et en supposant que ça va de soi que les autres l'aiment, à qui on n'oserait pas demander de la quitter, on pousse les premiers à détester ce pays parce qu'ils ne se sentent pas acceptés. Ils sont tout le temps contraints de prouver leur amour pour la France

\footnotetext{
1. Le concept d'État-nation renvoie à un État (une organisation politique) qui coïncide avec une nation (un groupe d'individus vivant sur un même territoire, ayant une langue commune, une même histoire et des mêmes valeurs) et où la nation (et non le monarque de droit divin) est la source du pouvoir souverain. Dans le cas de la France, l'« unité culturelle » (Choquet, 2015, p. 363) de la nation s'est constituée grâce à l'unification du territoire français après la Révolution. C'est donc la formation de l'État qui est à l'origine de la communauté de culture qui unit les membres de la nation et non l'inverse.

2. https://m.huffingtonpost.fr/2012/03/13/sarkozy-france-aime-quitte-banlieues_n_1340946.html
} 


\section{L'identité française entre repli sur soi et ouverture à l'autre Alain Finkielkraut vs François Durpaire}

alors que leurs compatriotes ne sont pas obligés de le faire. D'ailleurs, l'amour ne doit-il pas être réciproque ? Si la France leur demande de l'aimer, ne doit-elle pas elle aussi les aimer?

Cette question de l'amour est liée à une autre portant sur la double nationalité. Durpaire critique ceux qui préconisent la suppression de la binationalité en prétendant que les Français binationaux sont tiraillés entre leur appartenance à la France et les origines de leurs parents. Ils leur demandent alors de manifester leur volonté d'appartenir à la nation française en renonçant à leur nationalité d'origine. Pourquoi les oblige-t-on à choisir l'une des nationalités ? S'ils ont choisi de vivre en France, c'est qu'ils l'aiment déjà. Pourquoi leur demande-t-on alors de n'aimer qu'elle ? On peut être attaché à deux nations avec le même degré d'amour comme un enfant n'a pas à choisir entre son père et sa mère et les aime autant l'un que l'autre.

Le débat sur la double allégeance reflète la conviction que la manifestation des appartenances particulières compromet l'unité nationale. Ce qui n'est pas vrai puisqu'en 1940, des Français d'origine étrangère ont sacrifié leur vie et versé leur sang pour défendre le territoire français contre l'occupation allemande, manifestant ainsi leur attachement à la nation. Pour Durpaire, la cohésion nationale n'a rien à voir avec la composition de la population. C'est au contraire en demandant aux binationaux de renoncer à leur autre nationalité qu'on les pousse à se replier sur leur identité d'origine et à ne pas se considérer comme Français. En revanche, si on reconnaît que leur attachement à une autre nation ne les empêche pas d'être pleinement Français ${ }^{1}$, on renforcera chez eux la fierté d'être Français, surtout que ce sont eux qui revendiquent leur appartenance française et ce malgré les discriminations subies. C'est le cas aux États-Unis où l'appellation à trait d'union (Italian-American, Hispanic-American, AfroAmerican) associe « la fierté des origines et la fierté nationale » (Durpaire, 2012, p. 70). Durpaire critique le modèle d'intégration français qui est basé sur l'effacement des appartenances particulières et qui ne prend pas en compte la diversité culturelle. Il cherche à assimiler les étrangers à l'inverse du modèle multiculturaliste américain qui permet aux individus de conserver leur culture

\footnotetext{
1. Claude Goasguen voit que la double nationalité constitue un problème dans la mesure où la personne concernée participe « à la souveraineté nationale de deux ou trois pays en même temps ». Il faut alors au moins empêcher les binationaux d'accéder aux «fonctions gouvernementales ou de représentation » (Stainville, 2011) parce qu'ils seraient susceptibles d'avoir un conflit d'intérêt, remettant ainsi en cause leur loyauté envers la France.
} 


\section{L'identité française entre repli sur soi et ouverture à l'autre Alain Finkielkraut vs François Durpaire}

d'origine sans que cela nuise au vivre-ensemble. Ce modèle est rejeté en France parce qu'on doute de sa capacité d'intégrer les étrangers et on craint qu'il conduise à la fragmentation de la société en plusieurs communautés vivant à l'écart les unes des autres.

Durpaire trouve que la reconnaissance de la diversité (c'est-à-dire qu'on peut être à la fois Français et musulman, Français et Algérien, Français et Antillais, etc.) ne constitue aucun obstacle à l'intégration des binationaux et ne menace pas l'identité nationale. Leur donner la possibilité d'afficher leur identité d'origine et d'exprimer leur différence culturelle contribuera à renforcer leur sentiment d'appartenance à la nation. C'est ce qui s'est déjà passé en 1927 lorsque la France a assoupli les conditions d'attribution de la nationalité française ${ }^{1}$ sans que personne ne réclame que les immigrés européens naturalisés abandonnent leur nationalité d'origine. Pourquoi la diversité pose-t-elle problème aujourd'hui ? Pourquoi crée-t-elle des tensions au sein de la société ?

\section{Reconnaître la diversité culturelle : une nécessité pour la cohésion nationale}

Durpaire invite les Français à rectifier leur manière de voir les minorités issues de l'immigration et pour le faire, ils doivent au préalable accepter le changement, tolérer le métissage et respecter le droit à la différence culturelle. Durpaire soutient que la diversification de la population française n'est pas uniquement liée à l'immigration postcoloniale. Elle remonte à l'Ancien Régime où la France était constituée de provinces avec des langues, des cultures et des traditions différentes ${ }^{2}$. Après l'effondrement de la royauté et la centralisation du pouvoir par l'État, il a fallu créer une certaine homogénéité entre les différentes régions regroupées sous une même autorité politique. L'unité nationale s'est alors construite grâce à «l'imposition de normes et de lois communes ${ }^{3}$ » (Choquet, 2015 , p. 363) qui ne tiennent pas compte des particularismes provinciaux. Elle est

\footnotetext{
1. La durée de résidence en France a été réduite de 10 à 3 ans (Weil, 2003, p. 325) et les enfants nés d'une mère française et d'un père étranger étaient automatiquement Français. Il convient de rappeler que dans le Code civil de 1804, la femme française qui épouse un étranger perd du coup sa nationalité et acquiert celle de son mari. Comme la France a perdu beaucoup d'hommes lors de la Première Guerre mondiale, sans compter les handicapés, le mariage avec les étrangers était fréquent. Il fallait donc modifier la loi pour compenser la baisse démographique. (Weil, 2003, p. 322)

2. Pour plus de détails, voir Choquet, 2015, pp. 112-119.

3. Le français est devenu la langue de l'État, le Code civil s'est substitué aux coutumes provinciales, la monnaie s'est unifiée, un système unique des poids et mesures a été adopté et un système fiscal unique a été élaboré.
} 


\section{L'identité française entre repli sur soi et ouverture à l'autre Alain Finkielkraut $v s$ François Durpaire}

fondée sur l'abolition de tous les privilèges et le traitement identique des citoyens par les différentes institutions de l'État ${ }^{1}$. Si le multiculturalisme est un problème en France c'est parce que, historiquement, l'unité s'est formée aux dépens de la diversité culturelle. Cela revient à dire que l'uniformité éternelle de la France est une chimère.

À l'instar des individus, les communautés aussi changent avec le temps. La France n'est pas restée la même tout au long de son histoire. On n'a pas « une seule France» (Durpaire, 2012, p. 30) qui demeure identique malgré les changements mais plusieurs : la France monarchique, la France républicaine, la France chrétienne, la France laïque, etc. Il s'agit toujours de la France mais pas de la même France. Durpaire critique ici ceux qui cherchent dans le passé la preuve de la continuité de la France à travers les siècles et qui définissent l'identité nationale par des traits culturels qui semblent constants. Or, la France n'est pas figée, elle est en perpétuel changement. Elle a connu, selon lui, trois révolutions qui l'ont profondément marquée et qui ont fortement contribué au changement du mode de vie des Français ${ }^{2}$. La révolution politique de 1789 a favorisé l'unification du peuple autour de valeurs communes en faisant de la citoyenneté le fondement de l'État. La révolution sociale avec la lutte ouvrière au XIX $^{\mathrm{e}}$ siècle a conduit au « recul de l'agriculture » et à « la montée de l'urbanisation» (Todorov, 2012, p. 224) provoquant ainsi le changement des «paysages français » (Durpaire, 2012, p. 20). Après la chute du Mur de Berlin et l'ouverture du monde, on assiste à une révolution multiculturelle due à la montée de l'immigration postcoloniale et elle est en train de changer le visage de la France. La société française est de plus en plus mélangée, les références culturelles sont multiples, les habitudes culinaires et vestimentaires ne sont pas les mêmes pour tous les Français, les noms à consonance étrangère sont de plus en plus fréquents. Mais au lieu de mettre l'accent sur l'aspect négatif du changement, comme le fait Finkielkraut, Durpaire tient à souligner que cette diversité et cette pluralité sont une richesse pour la France. Les jeunes issus de l'immigration sont un atout pour le pays puisque, connaissant «plusieurs langues et plusieurs cultures » (Durpaire, 2012, p. 72), ils sont capables de « faire dialoguer [la France] avec le monde » (Durpaire, 2012, p.

1. Les Français ne sont plus sujets d'un roi, définis en fonction de leur appartenance à l'un des ordres de la société, mais des citoyens libres et égaux.

2. Finkielkraut lui-même a consacré tout un chapitre de L'Identité malheureuse à la critique de la technologie pour montrer comment l'identité française est menacée à l'ère du numérique. Passant plus de temps sur les réseaux sociaux, les jeunes lisent de moins en moins les classiques de la littérature ce qui risque d'entrainer la dégradation de la langue française. 


\section{L'identité française entre repli sur soi et ouverture à l'autre Alain Finkielkraut vs François Durpaire}

121). Il faut donc profiter de tous les talents que possède la France, leur donner la chance de construire leur vie et de contribuer au développement économique et culturel du pays. Il ne faut pas vivre dans la nostalgie du passé et répéter que c'était mieux avant. Le mythe du bon vieux temps reflète la peur de l'avenir et empêche de se projeter dans le futur :

L'histoire est une force. [...] Mais notre long passé serait un handicap [...] s'il n'était que le prétexte à ressasser ce que nous avons été. S'il nous empêchait de voir ce que nous gagnerions à assumer ce que nous sommes devenus. (Durpaire, 2012, p. 24)

Il ajoute, vers la fin de l'ouvrage, que « la grandeur de [la] nation [française] ne se jaugera pas à sa capacité de défense contre des emprunts extérieurs, mais à sa force d'adaptation. À son pouvoir d'accueil » (Durpaire, 2012, p. 121).

À l'ère de la mondialisation, la fermeture sur soi et la peur de s'ouvrir seront un facteur de déclin. Dès lors, il faut abandonner l'idée de la mono-identité au profit de celle de la pluri-identité qui correspond plus à un monde ouvert où les individus circulent librement. L'identité de chaque individu n'est ni stable ni définie une fois pour toutes. Elle évolue en fonction des groupes auxquels il appartient et qui varient selon le sexe, l'âge, la profession, le milieu social, la langue parlée, les habitudes alimentaires, les croyances religieuses et la nationalité.

Le "nous" se définit comme le rassemblement des gens avec qui on partage ces pratiques [sociales]. Je suis "musulmane" lorsque je mange halal ou observe le ramadan, mais je suis "femme" lorsque je sors entre copines. Je suis "Sénégalaise" lorsqu'un match oppose le Sénégal au Mali, ou "francophone" lorsque à Montréal je suis heureuse de me faire comprendre... (Durpaire, 2012, p. 73)

Chaque individu a donc une identité multiple composée de ses différentes appartenances. Pourquoi alors figer l'individu et réduire son identité à une seule appartenance tout en refusant de prendre en considération ses autres identifications? La nouvelle France ne doit pas se recroqueviller sur son passé et doit faire la place au pluralisme et reconnaître la diversité culturelle comme un élément constitutif de l'identité nationale. Autrement dit, la communauté nationale doit être inclusive et accepter l'idée de l'identité plurielle afin de 


\section{L'identité française entre repli sur soi et ouverture à l'autre Alain Finkielkraut vs François Durpaire}

favoriser le vivre-ensemble. Au lieu de se retourner vers le passé pour y trouver les racines des Français et de «s'accrocher à une identité épurée de toute évolution » (Durpaire, 2012, p. 74), il faut plutôt chercher dans le passé ce qui réunit les Français quelles que soient leur origine ou leur religion. C'est là qu'intervient le rôle de l'école, le lieu où se forge le lien qui unit les citoyens de la nation malgré la diversité de leurs ancrages culturels.

\section{Propositions pour développer le sentiment national chez les jeunes issus de l'immigration}

Si l'acquisition de la nationalité est le premier pas vers l'insertion de l'individu dans la communauté nationale, il faut nourrir chez lui un sentiment d'appartenance :

Dire que l'on "est Français", c'est se référer à l'État, à ses lois, son administration, ses institutions. [...] Dire "nous sommes la France", ce n'est plus seulement se référer à des papiers d'identité. C'est affirmer qu'il y a un "nous" qui transcende nos identités particulières. (Durpaire, 2012, p. 91)

Dans le système républicain français, l'école publique a toujours été perçue comme un outil d'unification culturelle. Son rôle ne se limite pas à transmettre des connaissances mais elle doit contribuer à forger le sentiment d'appartenance à la nation. Durpaire donne à titre d'exemple le cas de la $\mathrm{III}^{\mathrm{e}}$ République où l'enseignement de l'histoire de France était considéré comme une nécessité pour inculquer aux élèves l'amour de la patrie. Après la chute du Second Empire en 1870 et la défaite de la France dans la guerre contre l'Allemagne, il fallait rassembler tous les Français autour de la République afin de construire une nation forte capable de récupérer l'Alsace-Lorraine. Le Petit Lavisse pour les écoliers français (manuel scolaire utilisé entre 1884 et 1950) présentait ainsi l'histoire nationale sous la forme d'un récit d' « une aventure collective née avec les Gaulois » (Sévillia, 2009). Le mythe des ancêtres gaulois visait en quelque sorte à «créer un sentiment d'unité au-delà des différences » régionales. (Durpaire, 2012, p. 83) Il était plus tard considéré comme un moyen encourageant l'intégration des fils des immigrés européens puisque c'est en apprenant à l'école qu'on a des ancêtres communs que le sentiment d'appartenance se cultive et que des élèves provenant de différents pays peuvent sentir qu'ils font partie de la même communauté. 


\section{L'identité française entre repli sur soi et ouverture à l'autre Alain Finkielkraut vs François Durpaire}

À partir de la seconde moitié du XX $\mathrm{XX}^{\mathrm{e}}$ siècle, l'enseignement chronologique de l'histoire a été abandonné au profit d'une étude thématique de l'histoire, plus tournée vers le monde. L'histoire de France est d'ailleurs survolée car, dans le contexte de l'après-guerre et la décolonisation, le motif de l'enseignement de l'histoire est de former des citoyens capables de prendre du recul avec l'histoire contée et d'y porter un regard critique. Aujourd'hui, dans le nouveau contexte créé par la mondialisation, quelle histoire faut-il enseigner aux élèves?

Durpaire voit qu'il est actuellement nécessaire de réécrire l'histoire nationale en mettant davantage l'accent sur les liens de la France avec le monde. Aujourd'hui, les Français issus de l'immigration ne se reconnaissent pas dans l'histoire enseignée à l'école :

Comment me sentir Français, moi qui suis de parents vietnamiens, lorsque j'apprends à l'école que Diên Biên Phu a été une terrible défaite ? Oui, en mai 1954, l'armée française a perdu face au Viêtminh, mais cette défaite est-elle la mienne ? Dois-je adopter l'histoire de France comme mienne au détriment de mon histoire familiale ? Faut-il que je m'arrache une partie de moi-même pour être Français? (Durpaire, 2012, p. 34)

Pour résoudre ce dilemme, le nouveau récit national doit s'ouvrir à ceux qui en étaient exclus, tout en étant capable de relater l'« histoire commune » (Durpaire, 2012, p. 85) des Français de toutes les origines : «L'histoire enseignée à l'école doit être le carrefour de nos différentes mémoires, synthétiser et transcender la diversité de nos héritages. » (Durpaire, 2012, p. 81) Cette étape est nécessaire pour éviter que chaque communauté ait sa propre version de l'histoire et pour que les élèves issus de l'immigration puissent trouver leur place dans le récit national.

Pour arriver à cela, il faut admettre l'idée que la France n'est pas coupée du reste du monde et que son histoire interfère avec celle des autres. On peut, par exemple, en enseignant le règne de Louis XIV, faire le point sur la création de la ville de Saint-Louis-du-Sénégal par des marins normands en 1659 et montrer comment l'histoire de l'Afrique est liée à celle de la France. En revanche, il n'est pas admissible de passer sous silence la colonisation française sous prétexte que l'enseignement du passé colonial de la France produirait un effet inverse et empêcherait les jeunes de s'intégrer à la nation et d'avoir le sentiment de faire partie d'une communauté de destin. L'omission de cette partie de l'histoire les 


\section{L'identité française entre repli sur soi et ouverture à l'autre Alain Finkielkraut vs François Durpaire}

empêcherait, au contraire, de comprendre la place actuelle de la France dans le monde et de se réconcilier avec le passé ${ }^{1}$.

Par ailleurs, le nouveau récit national ne doit pas reproduire le mythe des ancêtres gaulois et doit, en contrepartie, mettre l'accent sur de nouvelles figures historiques qui seraient plus représentatives de la nation française aux racines multiples. Les Français, quelles que soient leurs origines, doivent être capables d'adopter des ancêtres communs. Le mot « ancêtre » ici n'a rien à voir avec le sang mais il englobe toutes les personnalités qui permettent aux Français de se sentir proches les uns des autres et de partager des racines communes malgré leur diversité apparente.

L'histoire de notre nation nous concerne tous. Elle nous prouve incessamment que notre identité n'est ni stable ni figée autour d'une seule couleur, d'une seule religion, et d'un panthéon, appris à l'école, de dix héros nationaux. Blancs ou Noirs, nous avons des ancêtres communs qui nous imposent de nous projeter ensemble vers un même avenir. (Durpaire, 2012, p. 89)

Ces ancêtres sont, selon Durpaire, toutes les personnes qui ont donné le jour aux principes sur lesquels se fonde la République. Il cite à titre d'exemple les Nèg'marrons, ces esclaves noirs qui ont pu s'échapper des plantations en 1791 et ont lutté contre l'esclavage, concrétisant ainsi les idéaux de liberté et d'égalité défendus par les philosophes des Lumières et prouvant leur universalité. Il mentionne aussi Olympe de Gouges, cette femme révolutionnaire qui a rédigé la Déclaration des droits de la femme et de la citoyenne en 1791, et Louis Delgrès, ce militaire français d'origine martiniquaise, qui, s'opposant au rétablissement de l'esclavage par Napoléon en 1802, a sacrifié sa vie pour défendre la liberté. Cette multiplicité d'ancêtres donnera l'occasion à ceux qui ne se reconnaissent pas dans les ancêtres gaulois de pouvoir s'identifier à des ancêtres issus de leur culture d'origine, ce qui les aidera en même temps à dépasser l'histoire coloniale.

Pour Durpaire, il est insignifiant de remonter loin dans le temps pour chercher les origines de la France actuelle. L'histoire de France commence avec la Déclaration des droits de l'homme et du citoyen de 1789 lorsque les États

1. Il faut souligner que la loi dite Taubira, promulguée le 21 mai 2001, reconnaît la traite négrière et l'esclavage comme un crime contre l'humanité. Elle constitue ainsi un premier pas vers l'intégration de la mémoire des descendants d'esclaves dans l'histoire nationale. 


\section{L'identité française entre repli sur soi et ouverture à l'autre Alain Finkielkraut vs François Durpaire}

généraux se sont constitués en Assemblée nationale et se sont proclamés représentants du peuple français. Cet événement est l'acte fondateur de la nation française dont la devise est «Liberté, égalité, fraternité ». Une nation où les privilèges n'ont aucune place, où la place de chacun dépend du mérite personnel et non du hasard de la naissance et où la fraternité se substitue à la hiérarchie sociale. C'est autour de ces valeurs que les Français doivent se rassembler en dépit de leurs diversités ce qui leur permettrait de s'approprier des ancêtres incarnant ces valeurs communes.

Mais Durpaire se demande si ces valeurs sont vraiment appliquées en France. La société française est inégalitaire tout comme elle l'était avant 1789. Les jeunes issus de l'immigration ont le sentiment qu'ils n'ont pas leur place dans la société et qu'ils n'ont pas les mêmes chances que leurs compatriotes français. Ils subissent des discriminations en matière de logement ou de travail. Ils vivent dans des quartiers pauvres, marqués par la violence et la délinquance, une sorte de «ghettos» (Durpaire, 2012, p. 107) qui regroupent les familles d'origine étrangère vivant dans la précarité et possédant leur propre culture. Ces conditions difficiles ne favorisent pas la réussite scolaire et certains élèves, ne trouvant pas dans leur entourage des «exemples positifs» à imiter, fuient l'école pour « rejoindre les réseaux » (Durpaire, 2012, p. 82) criminels des banlieues. Et même ceux qui parviennent à obtenir un diplôme ont moins de chance de trouver un emploi en raison de leur origine étrangère ou de leur lieu de vie.

Pour que ces jeunes se sentent Français, il faut les intégrer dans la société et leur donner l'occasion d'y participer. Pour cela, il faut «lutter contre la ségrégation » sociale et encourager « la mixité réelle »(Durpaire, 2012, p. 107) :

Décommunautariser la France signifie qu'on puisse se rencontrer dans les mêmes quartiers, dans les mêmes immeubles, quelle que soit l'origine sociale ou culturelle. (Durpaire, 2012, p. 111)

Les classes les plus défavorisées gagneront à côtoyer les plus aisées car elles auront l'occasion de rencontrer des modèles de réussite qui les motiveront à faire de leur mieux. Pour rendre possible la cohabitation des riches et des pauvres dans les mêmes quartiers et pour que leurs enfants puissent fréquenter les mêmes écoles, il faut mettre fin aux préjugés et aux stéréotypes qui mettent à mal le vivreensemble et qui risquent d'enfermer les jeunes issus de la diversité dans leur identité. En outre, l'école, étant « la matrice d'une société plus juste» (Durpaire, 


\section{L'identité française entre repli sur soi et ouverture à l'autre Alain Finkielkraut vs François Durpaire}

2012, p. 82), doit assurer l'égalité des chances entre les élèves quelle que soit leur origine sociale. Elle doit, d'une part, aider les jeunes issus des quartiers populaires à cultiver leur confiance en leurs capacités de réussir et de poursuivre leurs études. Elle doit, d'autre part, faciliter leur accès aux filières sélectives en leur fournissant toutes les informations nécessaires sur ces filières et en les y préparant comme on fait avec les élèves des établissements les plus favorisés.

Quant aux discriminations à l'embauche, Durpaire suggère que les facteurs discriminatoires (tels le patronyme, la couleur de la peau, le quartier d'origine) soient utilisés pour intégrer les jeunes issus de la diversité en leur réservant une certaine proportion de places dans les entreprises et les institutions. Cela nécessite un changement dans la manière de percevoir l'égalité. Dans une société multiculturelle, il ne suffit pas que la loi soit la même pour tous les citoyens mais il faut qu'elle prenne en compte les inégalités entre eux car, en traitant indifféremment deux personnes inégales, elle ne fait que renforcer les inégalités au lieu de les corriger ${ }^{1}$. Pour que l'égalité soit réelle, il faut que « l'égalité devant la loi » aille de pair avec «l'égalité par la loi » (Durpaire, 2012, p. 95). Ceux qui sont différents de la majorité ont le droit à un traitement différencié. Il faut donc penser à mettre en œuvre des «mesures compensatoires » (Choquet, 2015, p. 22) qui ont pour effet de réduire les éventuelles inégalités engendrées par l'application de la même loi à tous les citoyens et d'assurer l'égal accès de tous aux droits sociaux. Cette réforme de la loi est nécessaire pour améliorer l'intégration économique et sociale des jeunes issus de l'immigration et pour renforcer le sentiment d'appartenance chez eux.

À la lumière de tout ce qui précède, il s'avère que nous sommes devant deux visions antagonistes de l'identité française. Celle de Finkielkraut rejette le multiculturalisme, vu comme une source de dégénérescence de l'identité nationale, et défend le droit des Français de protéger leur propre culture contre toutes les pratiques étrangères qui la mettent en péril. Pour lui, la violence des jeunes des banlieues, le port du voile, l'inégalité homme-femme sont incompatibles avec la culture française dont les principales composantes sont la

1. Sabine Choquet fait remarquer que la neutralité de la loi est un leurre parce qu'elle n'est en réalité que «le reflet de la culture de la majorité » (Choquet, 2015, p. 177). Elle donne à titre d'exemple «le choix des jours fériés » (Choquet, 2015, p. 22) qui est déterminé par le «calendrier chrétien» ce qui fait que les chrétiens sont « favorisés par cette mesure par rapport aux juifs ou aux musulmans. [...] La reconnaissance égalitaire impliquera que leurs croyances religieuses soient prises en considération au même titre que celles des chrétiens » (Choquet, 2015, p. 148). 


\section{L'identité française entre repli sur soi et ouverture à l'autre Alain Finkielkraut vs François Durpaire}

civilité, la galanterie, la mixité et la laïcité. L'autre, ayant une tradition culturelle différente, n'a de place dans la communauté nationale qu'au prix de l'assimilation. Mais Finkielkraut juge les musulmans de France inassimilables et trouve que leur existence bafoue l'identité française. Alors il les rejette hors la nation portant ainsi atteinte à la liberté individuelle et à l'égalité entre les différents groupes ethnoculturels qui forment la société.

Durpaire, quant à lui, a une vision plus ouverte de l'identité française qui repose sur la volonté des individus de faire partie de la nation ainsi que sur leur attachement à des valeurs communes sans être obligés de renoncer à une part d'eux-mêmes. Il rejoint ainsi Ernest Renan (Renan, 1882, pp. 50-51) pour qui la volonté de vivre en commun est le fondement de toute nation. Mais si Renan lui ajoute l'existence d'un passé commun, Durpaire voit que ce passé est à construire à travers la réécriture de l'histoire nationale. Il reconnaît, en outre, le rôle qui incombe à l'État dans la réussite du processus d'intégration et essaie de tracer les grandes lignes d'une politique de lutte contre les discriminations. Il aspire à une «République multiculturelle» (Thuram, Durpaire, Diallo et al., 2010) où les principes universels dont elle se réclame vont de pair avec la reconnaissance de sa pluralité interne, unique moyen pour rendre les Français unis dans la diversité.

\section{Bibliographie :}

- ALGALARRONDO, Hervé. (2014, 18 septembre). « Laissés-pour-compte : La France périphérique. Un entretien avec Christophe Guilluy ». Le Nouvel Observateur, pp. 80-82.

- CASTILLO, Monique. (2014, décembre). «Identité nationale et identité européenne. Un destin commun ?». Études, pp. 53-61. URL : https:www.cairn.info/revue-etudes-2014-12-page-53.htm

- CHOQUET, Sabine. (2015). Identité nationale et multiculturalisme. Deux notions antagonistes ?. Paris, Classiques Garnier, Coll. « Littérature, Histoire, Politique ».

- DEBOMY, Frédéric. (2017). Finkielkraut, la pensée défaite. Paris, Éditions Textuel, Coll. « Petite encyclopédie critique ».

- DURPAIRE, François. (2012). Nous sommes tous la France! Essai sur la nouvelle identité française. Paris, Philippe Rey. 


\section{L'identité française entre repli sur soi et ouverture à l'autre Alain Finkielkraut vs François Durpaire}

- FINKIELKRAUT, Alain. (1987). La Défaite de la pensée. Gallimard, Coll. «Folio/Essais ».

- FINKIELKRAUT, Alain. (2013). L'Identité malheureuse. Paris, Stock, Folio $\mathrm{n}^{0} 5912$.

- HABIB, Claude. (2018, 9 février). «La galanterie était le soft power de la monarchie française ». Revue des deux mondes [En ligne], consulté le 17 juillet 2019. URL :

https://www.revuedesdeuxmondes.fr/claude-habib-galanterie-etait-softpower-de-monarchie-francaise/

- https://m.huffingtonpost.fr/2012/03/13/sarkozy-france-aime-quittebanlieues_n_1340946.html

- JAMIN, Jérôme. (2015, janvier-février). « Racisme, islam et langage codé ». Politique, Revue de débats, $\mathrm{n}^{\circ}$ 88, pp. 34-39.

- LÉVI-STRAUSS, Claude. (1983). Le Regard éloigné. Paris, Plon.

- LÉVY, Elisabeth. (2011, 15 décembre). «Alain Finkielkraut, "Qu'est-ce qu'être français ?” ». Le Point [En ligne], consulté le 26 juin 2019. URL: https://www.lepoint.fr/politique/alain-finkielkraut-qu-est-ce-qu-etre-francais15-12-2011-1408666_20.php

- Ligne droite. (2018, 24 août). «L'immigration de peuplement conduit à une catastrophe civilisationnelle». Consulté le 30 juillet 2020. URL : https://lignedroite.club/limmigration-de-peuplement-conduit-a-unecatastrophe-civilisationnelle/

- PERRAULT, Guillaume. (2013, 22 octobre). «Immigration : la controverse du droit du sol ». Le Figaro [En ligne], consulté le 15 juillet 2019. URL : http://www.lefigaro.fr/politique/2013/10/22/01002-20131022ARTFIG00585immigration-la-controverse-du-droit-du-sol.php

- RENAN, Ernest. (1882). Qu'est-ce qu'une nation? URL: classiques.uqac.ca/classiques/renan_ernest/qu_est_ce_une_nation/renan_quest _ce_une_nation.pdf

- SÉVILLIA, Jean. (2009, 3 octobre). «Lavisse, l'instituteur national ». Le Figaro [En ligne], consulté le 28 juin 2019. URL : http://www.lefigaro.fr/livres/2009/10/03/03005-20091003ARTFIG00057lavisse-1-instituteur-na-tional-.php

- STAINVILLE, Raphaël. (2011, 17 juin). « 130000 naturalisations par an, c'est trop ». Le Figaro [En ligne], consulté le 8 septembre 2020. URL : 


\section{L'identité française entre repli sur soi et ouverture à l'autre Alain Finkielkraut vs François Durpaire}

http://www.lefigaro.fr/lefigaromagazine/2011/06/18/0100620110618ARTFIG00585-130-000-naturalisations-par-an-c-est-trop.php

- STOCZKOWSKI, Wiktor. (2007, avril-juin). «Racisme, antiracisme et cosmologie lévi-straussienne. Un essai d'anthropologie réflexive ». L'Homme, $\mathrm{n}^{\mathrm{o}}$ 182, pp. 7-51. URL : http://journals.openedition.org/lhomme/29406

- TAGUIEFF, Pierre-André. (1985, décembre). «Le néo-racisme différentialiste. Sur l'ambiguité d'une évidence commune et ses effets pervers : l'éloge de la différence ». Langage \& société, $\mathrm{n}^{\circ} 34$, pp. 69-98.

- TAGUIEFF, Pierre-André. (2015). La Revanche du nationalisme. Néopopulistes et xénophobes à l'assaut de l'Europe. Paris, Presses universitaires de France.

- TERESTCHENKO, Michel. (2013, 3 novembre). «Les très tristes heures d'Alain Finkielkraut». Revue du MAUSS permanente [En ligne], consulté le 5 décembre 2019. URL :

https://www.journaldumauss.net/?Les-tres-tristes-heures-d-Alain

- THURAM, Lilian, DURPAIRE, François, DIALLO, Rokhaya et al. (2010). Appel pour une république multiculturelle et postraciale, suivi des 100 propositions pluricitoyennes. Éditions Respect Mag.

- TODOROV, Tzvetan. (2008). La Peur des barbares. Au-delà du choc des civilisations. Paris, Éditions Robert Laffont, Coll. « Le Livre de Poche», Série «biblio essais ».

- $\quad$-- $\quad$-- (2012). Les Ennemis intimes de la démocratie. Paris, Éditions Robert Laffont, Coll. « Le Livre de Poche ».

- WEIL, Patrick. (2003, mars). « Nationalité : l'originalité française ». Études, Tome 398, pp. 321-331. URL : https://www.cairn.info/revue-etudes-2003-3page-321.htm 


\title{
L'identité française entre repli sur soi et ouverture à l'autre \\ Alain Finkielkraut vs François Durpaire
}

\author{
الهوية الفرنسية بين الإنغلاق على الذات والإنفتاح على الآخر

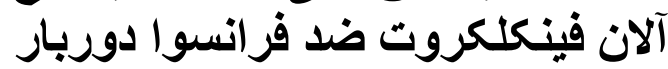

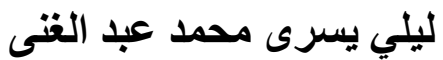 \\ قسم اللغة الفرنسية، كلية الآداب، جامعة الإسكندرية. \\ laila.yosry@alexu.edu.eg
}

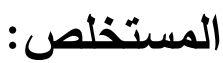

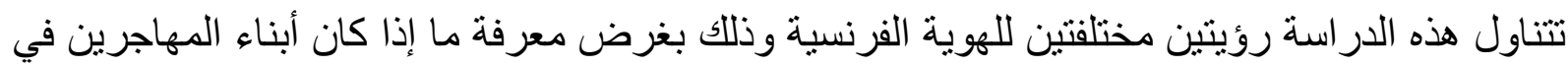

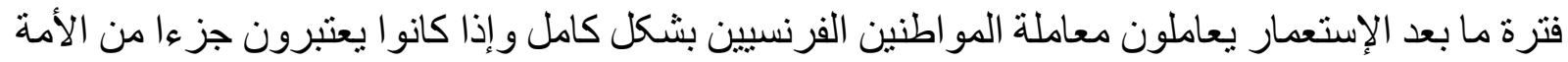

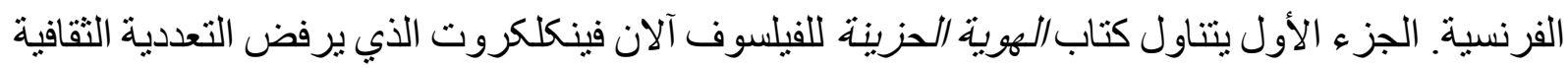

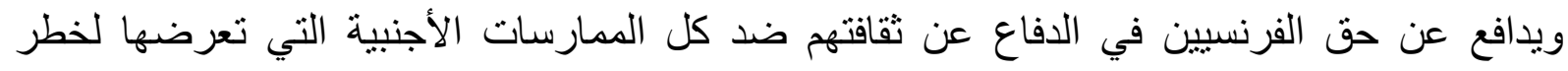

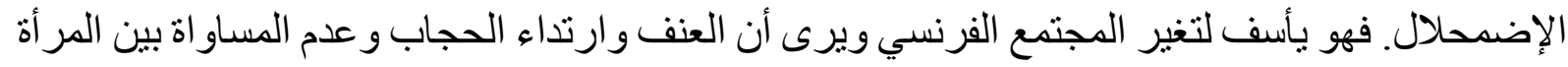

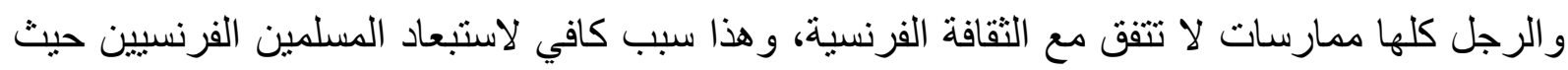

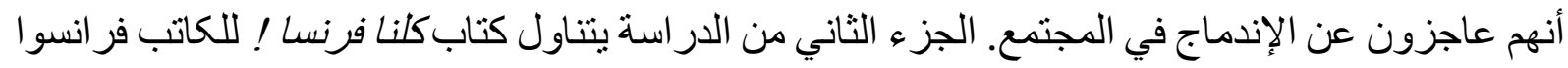

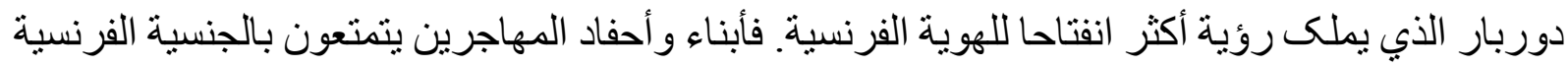

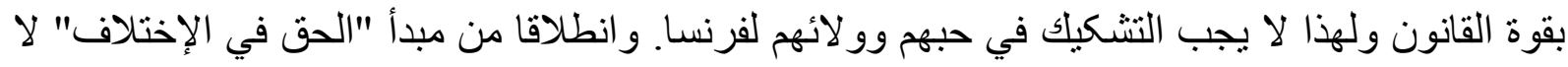

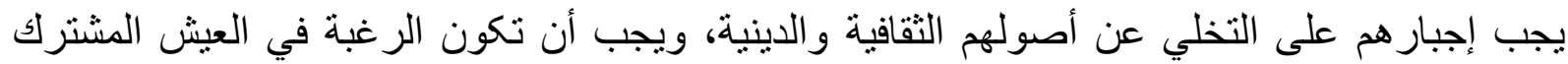

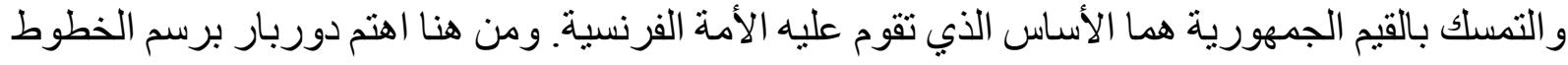

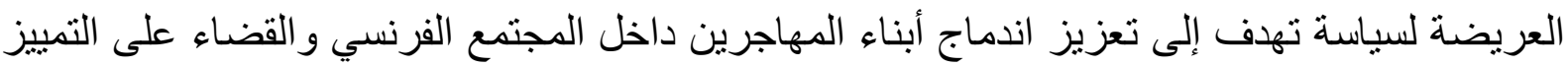
على أمل أن يصبح الفرنسيون متحدين رغم اختلافاتهم.

الكلمات الدالة: الهوية ؛ التعددية الثقافية ؛ الإندماج ؛ الهجرة ؛ العيش المشترك 